\title{
Outcomes of endoscopic surgery compared with open surgery for carpal tunnel syndrome among employed patients: randomised controlled trial
}

Isam Atroshi, Gert-Uno Larsson, Ewald Ornstein, Manfred Hofer, Ragnar Johnsson, Jonas Ranstam

\begin{abstract}
Objectives To compare endoscopic and open carpal tunnel release surgery among employed patients with carpal tunnel syndrome.

Design and setting Randomised controlled trial at a single orthopaedic department.

Participants 128 employed patients aged 25-60 years with clinically diagnosed and electrophysiologically confirmed idiopathic carpal tunnel syndrome.
\end{abstract}

Main outcome measures The primary outcome was severity of postoperative pain in the scar or proximal palm and the degree to which pain or tenderness limits activities, each rated on a 4 point scale, transformed into a combined score of 0 (none) to 100 (severe pain or tenderness causing severe activity limitation). The secondary outcomes were length of postoperative work absence, severity of symptoms of carpal tunnel syndrome and functional status scores, SF-12 quality of life score, and hand sensation and strength (blinded examiner); follow-up at three and six weeks and three and 12 months.

Results 63 patients were allocated to endoscopic surgery and 65 patients to open surgery, with no withdrawals or dropouts. Pain in the scar or proximal palm was less prevalent or severe after endoscopic surgery than after open surgery but the differences were generally small. At three months, pain in the scar or palm was reported by 33 patients (52\%) in the endoscopic group and 53 patients $(82 \%)$ in the open group (number needed to treat $3.4,95 \%$ confidence interval 2.3 to 7.7 ) and the mean score difference for severity of pain in scar or palm and limitation of activity was 13.3 (5.3 to 21.3). No differences between the groups were found in the other outcomes. The median length of work absence after surgery was 28 days in both groups. Quality of life measures improved substantially.

Conclusions In carpal tunnel syndrome, endoscopic surgery was associated with less postoperative pain than open surgery, but the small size of the benefit and similarity in other outcomes make its cost effectiveness uncertain.

\section{Introduction}

Surgery for carpal tunnel syndrome is one of the most often performed procedures. In the United States, more than 350000 carpal tunnel release procedures are performed annually. ${ }^{1}$ The largest proportion is done in working people. Open carpal tunnel release may result in prolonged pain at the scar and proximal palm. In a randomised study of open surgery versus splinting, 55 of 87 patients in the surgery group had painful or hypertrophic scar or pillar pain. ${ }^{2}$ The length of work absence after carpal tunnel surgery varies, depending on factors that still are not well understood. One such factor might be the severity of postoperative pain. Carpal tunnel syndrome is one of the most common medical causes of work absence, with almost half of all cases, including non-surgical, having an annual work loss of more than 30 days. ${ }^{3}$ The longer periods probably included work absence after surgery. ${ }^{4}$ The economic consequences of prolonged postoperative sick leave can therefore be substantial.

Endoscopic procedures to release the carpal tunnel have been introduced with the presumed advantage of decreased postoperative pain and subsequently faster return of patients to work. ${ }^{5}{ }^{6}$ No previous randomised studies comparing endoscopic and open carpal tunnel release have specifically assessed postoperative hand pain with a patient reported outcome measure. A few studies reported results of postoperative work absence favouring endoscopic surgery, ${ }^{6-8}$ but others did not show such differences. ${ }^{9}$ These studies had limitations, mainly inappropriate randomisation methods and inadequate numbers of employed patients. We compared open and endoscopic carpal tunnel release among employed patients with carpal tunnel syndrome with regard to postoperative pain, quality of life outcomes, and length of work absence after the operation.

\section{Methods}

\section{Eligibility criteria}

The inclusion criteria were primary idiopathic carpal tunnel syndrome, age 25-60 years, currently employed, duration of symptoms of at least three months, inadequate response to six weeks' treatment with wrist splint, symptoms of classic or probable carpal tunnel syndrome according to the diagnostic criteria in the Katz hand diagram, ${ }^{10}$ and nerve conduction test showing median neuropathy at the wrist (distal motor latency $\geq 4.5$ milliseconds, wrist-digit sensory latency $\geq 3.5$ milliseconds, or sensory conduction velocity at the carpal tunnel segment $<40$ metres/second $)^{11}$ but no other abnormalities.

The exclusion criteria were inflammatory joint disease, diabetes mellitus, thyroid disorder, pregnancy, trauma to the affected hand during the preceding year, previous carpal tunnel release surgery in the affected hand, carpal tunnel release surgery in the contralateral hand during the preceding year, symptoms of carpal tunnel syndrome in the contralateral hand not adequately relieved by splint at the time of enrolment, current sick leave because of disorders other than carpal tunnel 
syndrome, and inability to complete questionnaires because of language problem or cognitive disorder.

\section{Recruitment and randomisation}

We did the study at a single centre, orthopaedic department with a catchment area of 170000 population. Patients were recruited among those referred by primary care doctors because of symptoms of carpal tunnel syndrome. Eligible patients were enrolled by the examining orthopaedic surgeon. Each patient was given full verbal and written information about the trial, and informed consent was obtained. Patients were allowed to enter the trial only once. The recruited patients were scheduled for surgery by a nurse and were assigned to a treatment group at the operating room immediately before surgery according to a computer generated randomisation list in blocks of eight. At the operating room the surgeon (with no knowledge of block size) opened the lowest numbered of sequentially numbered sealed opaque envelopes containing the identity of the operative method.

\section{Interventions}

Surgeons used the two portal endoscopic method (Smith \& Nephew Endoscopy, Andover, Massachusetts, USA). They did all procedures under local anaesthaesia, injected subcutaneously at the proximal and distal portals (endoscopic) or along the length of the incision (open), and they used a tourniquet. Each of the two skin incisions in the endoscopic procedure was $1 \mathrm{~cm}$ long. With the endoscope inserted from the distal portal and a hook knife inserted from the proximal portal, the transverse carpal ligament was divided from its distal edge to its proximal edge. The incision in the open procedure extended from about $1 \mathrm{~cm}$ proximal to $3 \mathrm{~cm}$ distal to the wrist crease. The transverse carpal ligament was divided; no additional procedures were performed. After both procedures, a soft dressing was applied and patients were advised by the surgeon to begin immediate finger range of motion exercises and to use the hand for daily activities as tolerated. Dressing and sutures were removed 10 days postoperatively. No physical or occupational therapy was prescribed (in accordance with clinical practice).

\section{Outcome measures}

The patients were evaluated with disease specific and quality of life questionnaires and physical examination at baseline (during the week before surgery) and at three weeks, six weeks, and three months, and with the questionnaires at 12 months after surgery.

\section{Primary outcome}

The primary outcome was the severity of postoperative pain experienced in the scar and proximal palm and the degree to which activity related pain in scar and palm or tenderness caused limitation of activity. This was measured with a two item pain scale (adapted from the short form 36 questionnaire (SF-36) bodily pain scale) previously shown to have high internal consistency. ${ }^{12}$ The first item asked the patients to rate the severity of pain in the scar or proximal palm on a 4 point scale (none, mild, moderate, severe). The location of the pain was specified to the scar and proximal palm in order to assess pain related to surgery rather than possible residual pain caused by nerve compression. The second item asked patients to rate the degree to which activity related pain or tenderness in the scar or proximal palm caused limitation of activities on a 4 point scale (no pain or tenderness on activity and no limitations, pain or tenderness on activity but causing no limitation of activity, pain or tenderness causing some limitation, pain or tenderness causing much limitation). Item responses were transformed, as described for similar scales ${ }^{13}$ into a score that may range from 0 (no pain or tenderness in scar or proximal palm and no activity limitation) to
100 (severe pain in scar or proximal palm and severe activity limitation because of pain or tenderness). A mean score difference of 8.3 points in favour of a group would correspond to one of every two patients, and a mean difference of 11.1 points would correspond to two of three patients, having less pain or activity limitation equal on average to one level (for example, mild pain versus moderate pain, no activity limitation versus some limitation) than the other group.

\section{Secondary outcomes}

The secondary outcomes were the length of work absence after surgery, the carpal tunnel syndrome questionnaire's symptom severity score and functional status score, the SF-12 physical health score, and changes in hand sensation and strength.

\section{Carpal tunnel syndrome questionnaire}

This was completed before surgery and at three weeks, six weeks, three months, and 12 months after surgery. The carpal tunnel syndrome questionnaire is a widely used, disease specific measure shown to be reliable, valid, and responsive in patients with carpal tunnel syndrome. ${ }^{12}{ }^{14}$ The symptom severity scale (11 items) concerns severity and frequency of symptoms (night and daytime numbness, tingling, pain, weakness). The functional status scale (eight items) concerns difficulties in performing specified activities (writing, holding a book, buttoning clothes, gripping the telephone handle, opening jars, doing household chores, carrying a grocery bag, bathing, and dressing). Each item has five response options ranging from 1 (no symptom or no difficulty in performing the activity) to 5 (most severe symptom or inability to perform the activity). The symptom severity and functional status score is the mean of all answered items in each scale; higher score indicates worse symptoms or disability. ${ }^{12} 14$

\section{SF-12}

The SF-12 was completed before surgery and at three months and 12 months after surgery. The SF-12 is a measure of health status and quality of life with 12 items generating a physical health component summary score and a mental health component summary score, the population norms of which have a mean of 50 and standard deviation of 10 ; higher score indicates better health. ${ }^{15}$

\section{Absence from work after the operation}

The patients answered a questionnaire before the operation, inquiring about whether the patient's work demanded heavy lifting daily and about the average time during a usual working day their work demanded using excessive force with the hand, working with excessively flexed or extended wrist, repetitive hand or wrist motion, using keyboard or handheld vibratory tools, and working in a cold environment or holding cold objects. In Sweden, all employees who are unable to work because of sickness are, from the second day of sickness, entitled to sick pay from the employer for the first 14 days and thereafter to sickness benefit from the state social insurance office for up to one year, after which the benefit may continue or be changed to sickness compensation. We retrieved the number of days from surgery to patient's return to work and of any prior sick leave days from the social insurance office. For the analysis, we defined the duration of work absence as the number of days from surgery until partial or total return to work. The addition of days with partial sick leave summed into full sick leave days gave similar results. Preoperative sick leave was defined as complete absence from work. 


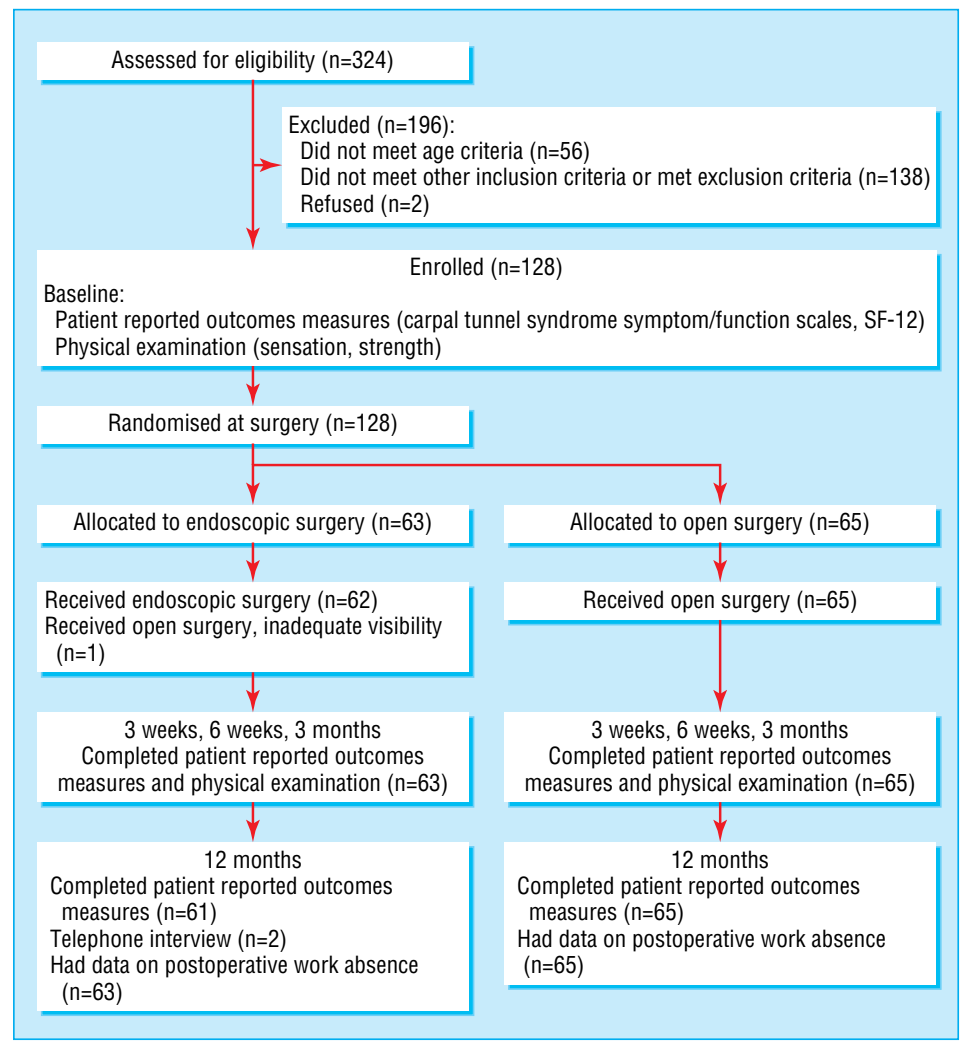

Fig 1 Flow of trial participants and the outcome measures

\section{Physical examination}

The same physical therapist with five years' experience in hand therapy conducted the preoperative and all postoperative examinations. The therapist performed Semmes-Weinstein monofilament and 2 point discrimination tests of sensation on the radial and ulnar aspects of each finger; 2 point discrimination testing was started with a distance of $4 \mathrm{~mm}$ and successively increased if necessary by $2 \mathrm{~mm}$. Grip strength and 3 point pinch strength, measured with the Baseline dynamometer and pinch gauge (Chattanooga Group, Hixson, Tennessee, USA), respectively, were recorded (three trials for each hand). Before each postoperative examination, the patients were instructed not to discuss the type of operation and had their palm and distal forearm covered with a stockinette (an elastic, sleeve-like dressing) concealing the scars. The assessor was thus blinded to the surgical method.

\section{Sample size}

A pretrial calculation of the number of patients showed that with $80 \%$ statistical power, $5 \%$ significance level, and two sided tests the study could detect a true difference of 10 points on the postoperative pain score (assumed standard deviation 20) and of 10 sick leave days (assumed standard deviation 20) between the two groups, with a sample size of 128 patients. ${ }^{16}$

\section{Statistical analyses}

We performed and reported statistical tests according to the intention to treat principle. We compared the postoperative pain scores for the two groups with analysis of covariance adjusting for age, sex, dominance of the operated hand, preoperative work status, and baseline symptom severity score. We determined the proportion of patients for each self rated pain category and calculated the number needed to treat, based on the number of patients reporting pain in the scar or proximal palm at three months in each group. ${ }^{17}{ }^{18}$ We performed mixed model analysis on repeated measures of postoperative pain score, change scores for severity of symptoms of carpal tunnel syndrome, functional status, SF-12, or changes in sensation, and strength as dependent variables, and group, follow-up time, and their interaction as fixed factors and the subjects as random factors. The mixed model analysis included age, sex, dominance of the operated hand and each dependent variable's preoperative value as covariates (for postoperative pain, we also included the preoperative symptom severity score as a covariate). In addition, we calculated the effect sizes for severity of symptoms and functional status at each follow-up time (mean change in scores divided by standard deviation of preoperative scores). ${ }^{17}{ }^{19}$ We used the Kaplan-Meier survival curve to compare the number of days of work absence in the two groups and the Mann-Whitney test to compare the duration of work absence for patients who were not on sick leave before surgery and for those who were.

\section{Results}

\section{Study population}

Recruitment started in January 1998 and was completed in December 2002. Of 324 patients screened for eligibility, 128 patients were eligible and were randomised; 65 patients to open release and 63 patients to endoscopic release (fig 1). The discrepancy in the number of patients between the two groups was caused by one mislabelled randomisation envelope. All patients received the allocated treatment except one patient in whom endoscopic release was converted during surgery into open release because of inadequate visibility. The two groups were generally similar in patient characteristics (table 1).

There were no withdrawals or drop-outs. Two patients (endoscopic group) did not return the 12-month carpal tunnel 
Table 1 Study population

\begin{tabular}{|c|c|c|}
\hline & Open surgery $(n=65)$ & $\begin{array}{l}\text { Endoscopic surgery } \\
\qquad(n=63)\end{array}$ \\
\hline Women (men) & $52(13)$ & $44(19)$ \\
\hline Mean age (range) in years & $44(25-59)$ & $44(26-59)$ \\
\hline Mean body mass index (SD) & $26.7(4.4)$ & $27.5(4.5)$ \\
\hline $\begin{array}{l}\text { No of patients in whom the dominant } \\
\text { hand was operated on in the trial (\%) }\end{array}$ & $54(83)$ & $48(76)$ \\
\hline $\begin{array}{l}\text { Mean duration of symptoms (range) in } \\
\text { months }\end{array}$ & 36 (4 to 240$)$ & 36 (3 to 240) \\
\hline \multicolumn{3}{|l|}{ Nerve conduction studies, mean (SD)* } \\
\hline Distal motor latency $(\mathrm{n}=62, \mathrm{n}=62)$ & $5.8(1.6)$ & $5.8(1.4)$ \\
\hline Distal sensory latency $(n=46, n=47)$ & $5.0(1.1)$ & $4.7(1.2)$ \\
\hline $\begin{array}{l}\text { Sensory conduction velocity in carpal } \\
\text { tunnel segment }(n=14, n=14)\end{array}$ & $27(13)$ & $19(14)$ \\
\hline \multicolumn{3}{|l|}{ Type of work, No (\%) of patients } \\
\hline Blue collar & $48(73.9)$ & $47(74.6)$ \\
\hline White collar & $14(21.5)$ & $13(20.6)$ \\
\hline Self employed & $3(4.6)$ & $3(4.8)$ \\
\hline \multicolumn{3}{|l|}{ Sick leave at enrolment } \\
\hline No (\%) of patients & $6(9)$ & $10(16)$ \\
\hline Median duration (range) in days & 71 (28 to 280$)$ & 88 (16 to 230$)$ \\
\hline \multicolumn{3}{|c|}{ Carpal tunnel release in contralateral hand within one year after surgery } \\
\hline No $(\%)$ of patients & $8(12)$ & $7(11)$ \\
\hline time interval, median (range) months & 5.5 (2 to 12$)$ & 6 (3 to 9$)$ \\
\hline
\end{tabular}

${ }^{\star}$ A few patients had only one of the three tests performed; sensory conduction velocity was measured as alternative to sensory latency.

syndrome and SF-12 questionnaires; these were interviewed by telephone. Because of at least one unanswered item, SF-12 scores could not be computed for four patients preoperatively (one from open and three from endoscopic group) and for two patients at 12 months (one from each group).

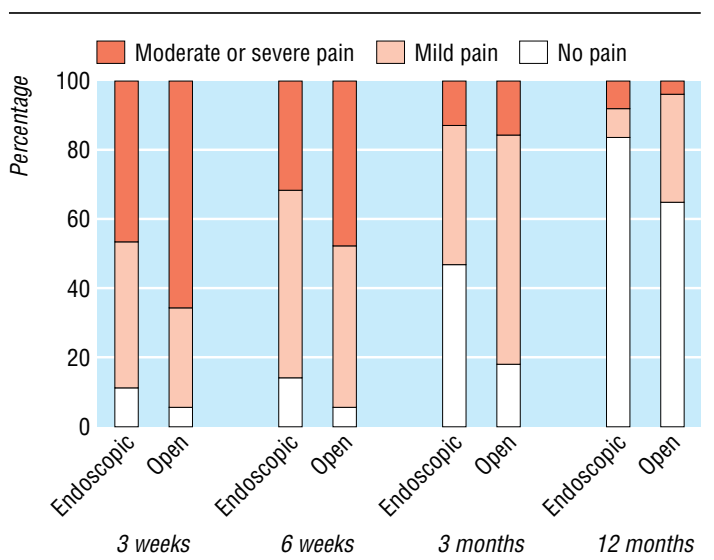

Fig 2 Proportion of patients for each self rated category of postoperative pain in the scar and proximal palm after endoscopic surgery and open surgery

\section{Postoperative pain}

The patients in the endoscopic group had less postoperative pain in the scar and proximal palm and activity limitation than those in the open group at three weeks, six weeks, and three months, but the differences were generally small (table 2). The changes from three weeks to the following follow-up times did not differ significantly between the groups. The number of patients reporting scar/palm pain at three months was $33(52 \%)$ in the endoscopic group and 53 (82\%) in the open group (fig 2), yielding a number needed to treat of $3.4(95 \%$ confidence interval 2.3 to 7.7 ).

\section{Severity of symptoms of carpal tunnel syndrome and} functional status scores

We found no significant differences in the carpal tunnel syndrome symptom severity scores or in score changes over time between the groups at any follow-up time (table 3 ). The number of patients who reported absence of numbness and tingling at three months was $47(72 \%)$ in the open group and $45(71 \%)$ in the endoscopic group. The endoscopic group had a better improvement in functional status score at three weeks postoperatively (a small difference that reached significance); we found no significant differences at the other follow-up times (table 3). For both groups the carpal tunnel syndrome symptom severity scores and the functional status scores improved significantly after surgery $(\mathrm{P}<0.0001)$.

\section{SF-12}

We found no significant differences in the SF-12 physical health score between the groups at any follow-up time (table 3). For both groups, the SF-12 physical health scores improved from baseline to three months and 12 months postoperatively, with the magnitude of improvement corresponding to moderate to large effect size.

\section{Work absence}

The two groups did not differ regarding the proportion of blue collar workers and white collar workers or the frequency of performing any of the work related activities inquired about at baseline. The Kaplan-Meier survival curve analysis showed no significant difference $(\mathrm{P}=0.9)$ between the groups in length of work absence after surgery (fig 3 ). The mean difference between the endoscopic and open group was two days $(95 \%$ confidence interval -10 to 14 days, $\mathrm{P}=0.8$ ). The 16 patients who were on sick leave before surgery had a significantly longer work absence after surgery than the 112 patients who were not on sick leave before surgery $(\mathrm{P}<0.001$; table 4$)$. The length of work absence after surgery for blue collar workers (mean 44, SD 36, median 36 days) was significantly longer than that for white collar employees (mean 19, SD 14, median 21 days) $(\mathrm{P}<0.001)$.

\section{Sensation and strength}

We found no significant differences between the two groups in the results of sensory measurements (table 5); in both groups

Table 2 Postoperative pain scores and pain related limitation of activity*

\begin{tabular}{|c|c|c|c|c|c|c|}
\hline \multirow[b]{2}{*}{ Time } & \multirow{2}{*}{$\begin{array}{l}\text { Mean (SD), open } \\
\text { surgery }\end{array}$} & \multirow{2}{*}{$\begin{array}{l}\text { Mean (SD), endoscopic } \\
\text { surgery }\end{array}$} & \multicolumn{4}{|c|}{ Difference between the two groups } \\
\hline & & & $\begin{array}{l}\text { Difference in means }(95 \% \\
\qquad \mathrm{Cl}) \dagger\end{array}$ & $P$ value & Change over timeł mean $(95 \% \mathrm{CI})$ & $P$ value \\
\hline 3 weeks & $60.5(23)$ & $52.1(23)$ & 8.6 (1.0 to 16.3$)$ & 0.028 & Reference & \\
\hline 6 weeks & $51.3(23)$ & $43.3(23)$ & $8.7(1.0$ to 16.4$)$ & 0.030 & $-0.8(-9.3$ to 7.8$)$ & 0.86 \\
\hline 3 months & $36.2(20)$ & $23.5(26)$ & 13.3 (5.3 to 21.3$)$ & 0.001 & $4.2(-4.3$ to 12.7$)$ & 0.33 \\
\hline 12 months & $13.9(22)$ & $8.7(21)$ & 5.8 (1.7 to 13.3$)$ & 0.13 & $-3.3(-11.8$ to 5.2$)$ & 0.45 \\
\hline
\end{tabular}

${ }^{*}$ Score range from 0 (no pain or tenderness in scar or proximal palm and no activity limitation) to 100 (severe pain in scar or proximal palm and severe activity limitation because of pain or tenderness).

†Analysis of covariance adjusting for baseline characteristics.

$\ddagger$ Mixed model analysis for difference between open and endoscopic groups in change over time (follow-up score minus baseline score) adjusting for baseline characteristics. 
Research

\begin{tabular}{|c|c|c|c|c|c|c|}
\hline \multirow[b]{2}{*}{ Score* } & \multicolumn{2}{|c|}{ Mean (SD) score } & \multicolumn{2}{|c|}{ Difference in change over time $†$} & \multicolumn{2}{|c|}{ Effect sizeł } \\
\hline & Open surgery & Endoscopic surgery & Mean $(95 \% \mathrm{Cl})$ & $P$ value & $\begin{array}{l}\text { Open } \\
\text { surgery }\end{array}$ & $\begin{array}{l}\text { Endoscopic } \\
\text { surgery }\end{array}$ \\
\hline \multicolumn{7}{|c|}{ Severity of symptoms of carpal tunnel syndrome } \\
\hline Baseline & $3.1(0.6)$ & $3.1(0.6)$ & Reference & & & \\
\hline 3 weeks & $1.8(0.5)$ & $1.8(0.5)$ & $-0.003(-0.18$ to 0.17$)$ & 0.98 & 2.0 & 2.1 \\
\hline 6 weeks & $1.7(0.5)$ & $1.7(0.5)$ & $0.05(-0.12$ to 0.23$)$ & 0.57 & 2.2 & 2.3 \\
\hline 3 months & $1.5(0.5)$ & $1.5(0.5)$ & $0.07(-0.11$ to 0.24$)$ & 0.44 & 2.5 & 2.7 \\
\hline 12 months & $1.4(0.5)$ & $1.4(0.6)$ & $0.005(-0.18$ to 0.17$)$ & 0.96 & 2.7 & 2.8 \\
\hline \multicolumn{7}{|c|}{ Carpal tunnel syndrome functional status } \\
\hline Baseline & $2.4(0.8)$ & $2.4(0.6)$ & Reference & & & \\
\hline 3 weeks & $2.3(0.9)$ & $2.0(0.8)$ & 0.22 (0.04 to 0.41$)$ & 0.02 & 0.13 & 0.59 \\
\hline 6 weeks & $1.6(0.5)$ & $1.5(0.5)$ & $0.07(-0.12$ to 0.25$)$ & 0.48 & 1.0 & 1.5 \\
\hline 3 months & $1.3(0.4)$ & $1.3(0.5)$ & $-0.02(-0.21$ to 0.14$)$ & 0.82 & 1.4 & 1.7 \\
\hline 12 months & $1.2(0.4)$ & $1.3(0.5)$ & $-0.08 \quad(-0.27$ to 0.11$)$ & 0.43 & 1.5 & 1.9 \\
\hline \multicolumn{7}{|c|}{ SF-12 physical health } \\
\hline Baseline & $42.5(9)$ & $44.2(8)$ & Reference & & & \\
\hline 3 months & $49.3(9)$ & $50.7(8)$ & $-1.1(-4.1$ to 1.9$)$ & 0.48 & 0.74 & 0.81 \\
\hline 12 months & $49.8(10)$ & 50.1 (9) & 0.43 (-2.6 to 3.5$)$ & 0.78 & 0.81 & 0.72 \\
\hline
\end{tabular}

*Score range; carpal tunnel syndrome, 1 (no symptoms or disability) to 5 (most severe symptoms or disability); SF-12, population norms have a mean of 50 and SD of 10.

†Mixed model analysis for difference between open and endoscopic groups in change over time (follow-up score minus baseline score) adjusting for baseline characteristics.

fEffect size, mean change scores (unadjusted) divided by baseline SD (0.2 considered small, 0.5 moderate, and 0.8 large clinical change). ${ }^{19}$

sensation improved, and the 95\% confidence intervals for the mean differences between the two groups in change over time for Semmes-Weinstein and two point discrimination were small (within 0.3) at all follow-up times (data not shown). We found no significant differences between the groups in changes in strength over time although there was a tendency for less strength loss in the endoscopic group (table 6). Grip strength, which decreased after surgery, was in both groups at almost preoperative level at three months and pinch strength showed a faster recovery and was better than before the operation at three months after it.

\section{Adverse events}

Three patients (women) had repeat surgery on the hand during the first year after the operation. The first patient (endoscopic) initially reported partial relief of symptoms, underwent open carpal tunnel release nine months after the procedure, and reported moderate improvement. The second patient (endoscopic) experienced worsening numbness and tingling in the two ulnar fingers after the procedure as well as prolonged pain and swelling in the palm, underwent open median and ulnar nerve

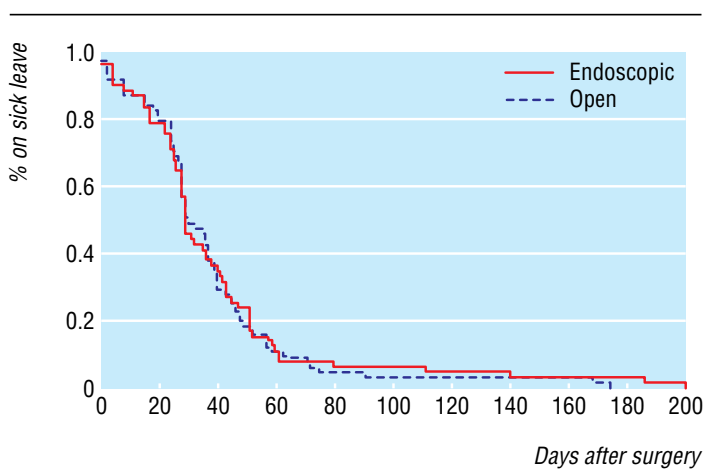

Fig 3 Kaplan-Meier survival curve for the duration of work absence after surgery decompression five months postoperatively but reported continued hand symptoms. The third patient (open) had a recurrence of symptoms, underwent repeat open release 12 months after the operation, and reported moderate improvement.

We observed no nerve, vascular, or tendon injuries, and no wound complications.

\section{Operating time}

The mean operating time (from tourniquet inflation to completed dressing) was 9 (SD 4) minutes for the endoscopic group and 15 (SD 3) minutes for the open group; the mean difference was -6 minutes $(95 \%$ confidence interval -5 to -7 minutes, $\mathrm{P}<0.001)$.

\section{Discussion}

Endoscopic surgery in carpal tunnel syndrome resulted in less postoperative pain in the scar and proximal palm and related limitation of activity than open surgery, but the differences were generally small. From the patient's perspective, reduced postoperative pain may be an important benefit. However, the largest difference, at three months, was $13 \%$ on a score that considered severity of pain and limitation of activity and corresponded to a number needed to treat of 3.4, which means four patients have to be treated for one to benefit (avoid scar or proximal palm pain of any severity). Moreover, the difference did not make any impact on the length of work absence after surgery. Either the magnitude of difference in pain was not large enough to influence the capacity to work or there might be other factors with a larger impact on return to work. Work status before surgery and type of work seem to be such factors.

\section{Comparison with other studies}

To our knowledge, this is the largest truly randomised study that compared pain and return to work after open and endoscopic

Table 4 Work absence after the operation, in days.

Not on sick leave before surgery

On sick leave before surgery

\begin{tabular}{|c|c|c|c|c|c|c|}
\hline & \multicolumn{3}{|c|}{ Not Oil SICK Iedve Defore surgery } & \multicolumn{3}{|c|}{ UII SICK Tedve Deture surgery } \\
\hline & No & Mean (SD) & Median (quartiles) & No & Mean (SD) & Median (range) \\
\hline Open surgery & 59 & $33(19)$ & 28 (23-44) & 6 & $76(74)$ & 37 (14-174) \\
\hline Endoscopic surgery & 53 & $28(16)$ & $28(17-39)$ & 10 & $84(62)$ & $51(25-200)$ \\
\hline
\end{tabular}




\section{Table 5 Hand sensation}

\begin{tabular}{|c|c|c|c|c|}
\hline \multirow{2}{*}{ Sensory test } & \multicolumn{2}{|c|}{ Median } & \multicolumn{2}{|c|}{ Ulnar } \\
\hline & Open surgery & Endoscopic surgery & Open surgery & Endoscopic surgery \\
\hline \multicolumn{5}{|c|}{ Semmes-Weinstein monofilament, mean (SD) ${ }^{*}$} \\
\hline Baseline & $2.0(0.7)$ & $2.1(0.7)$ & $1.5(0.6)$ & $1.5(0.7)$ \\
\hline 3 weeks & $1.5(0.6)$ & $1.6(0.7)$ & $1.3(0.5)$ & $1.3(0.5)$ \\
\hline 6 weeks & $1.4(0.6)$ & $1.6(0.6)$ & $1.2(0.4)$ & $1.2(0.4)$ \\
\hline 3 months & $1.5(0.6)$ & $1.6(0.7)$ & $1.2(0.5)$ & $1.3(0.6)$ \\
\hline \multicolumn{5}{|c|}{ Two point discrimination, mean (SD)* } \\
\hline Baseline & $4.5(0.9)$ & $4.7(1.1)$ & $4.3(0.6)$ & $4.5(0.8)$ \\
\hline 3 weeks & $4.1(0.3)$ & $4.3(0.6)$ & $4.2(0.4)$ & $4.3(0.5)$ \\
\hline 6 weeks & $4.1(0.3)$ & $4.3(0.5)$ & $4.2(0.3)$ & $4.3(0.6)$ \\
\hline 3 months & $4.1(0.4)$ & $4.2(0.5)$ & $4.1(0.4)$ & $4.2(0.4)$ \\
\hline \multicolumn{5}{|c|}{ Two point discrimination, № (\%)† } \\
\hline \multicolumn{5}{|c|}{ Baseline: } \\
\hline $4 \mathrm{~mm}$ & $38(60.3)$ & $35(55.6)$ & $47(74.6)$ & $43(68.2)$ \\
\hline $6 \mathrm{~mm}$ & $18(28.6)$ & $20(31.7)$ & 15 (23.8) & 17 (27) \\
\hline$\geq 8 \mathrm{~mm}$ & $7(11.1)$ & $8(12.7)$ & $1(1.6)$ & $3(4.8)$ \\
\hline \multicolumn{5}{|l|}{3 weeks: } \\
\hline $4 \mathrm{~mm}$ & 50 (78.1) & $49(77.8)$ & $54(84.4)$ & 47 (74.6) \\
\hline $6 \mathrm{~mm}$ & $14(21.9)$ & $12(19)$ & 10 (15.6) & $16(25.4)$ \\
\hline$\geq 8 \mathrm{~mm}$ & $0(0)$ & $2(3.2)$ & $0(0)$ & $0(0)$ \\
\hline \multicolumn{5}{|l|}{6 weeks: } \\
\hline $4 \mathrm{~mm}$ & $54(85.7)$ & $45(71.4)$ & 51 (81) & 51 (81) \\
\hline $6 \mathrm{~mm}$ & $9(14.3)$ & 18 (28.6) & 12 (19) & 12 (19) \\
\hline$\geq 8 \mathrm{~mm}$ & $0(0)$ & $0(0)$ & $0(0)$ & $0(0)$ \\
\hline \multicolumn{5}{|l|}{3 months: } \\
\hline $4 \mathrm{~mm}$ & $51(84.1)$ & $51(80.9)$ & $54(85.7)$ & 55 (87.3) \\
\hline $6 \mathrm{~mm}$ & $10(15.9)$ & $11(17.5)$ & $9(14.3)$ & 8 (12.7) \\
\hline$\geq 8 \mathrm{~mm}$ & $0(0)$ & $1(1.6)$ & $0(0)$ & $0(0)$ \\
\hline
\end{tabular}

${ }^{*}$ Mean (SD) for the three and half radial fingers or one and half ulnar fingers, innervated by median and ulnar nerve, respectively.

†No (\%) of patients with two point discrimination value of $4 \mathrm{~mm}$ in all median or ulnar nerve innervated fingers or $6 \mathrm{~mm}$ or $\geq 8 \mathrm{~mm}$ in at least one of the fingers.

surgery for carpal tunnel syndrome. A recent meta-analysis of studies published in 2000 identified 13 reportedly randomised studies comparing endoscopic and open carpal tunnel release, 10 of which did not report the randomisation method used and the remaining three had used inappropriate randomisation methods. ${ }^{20}$ Three more recent studies have been published. One study reported a shorter time for patients' return to work after one portal endoscopic release than open release (median, 18 versus 38 days). ${ }^{8}$ Although the study was described as randomised, it included patients who re-entered the study because of symptoms in the contralateral hand and had the same type of procedure without randomisation. Because the two hands were analysed as independent entities, a potentially high proportion of the hands were not randomised; 70 hands (17 non-randomised) in the endoscopic group and 57 hands (eight non-randomised) in the open group were included in the analy-

Table 6 Hand strength

\begin{tabular}{|c|c|c|c|c|}
\hline & \multicolumn{2}{|c|}{ Mean strength (SD) } & \multicolumn{2}{|c|}{ Difference in change over time ${ }^{*}$} \\
\hline & Open surgery & $\begin{array}{c}\text { Endoscopic } \\
\text { surgery }\end{array}$ & Mean strength $(95 \% \mathrm{Cl})$ & $P$ value \\
\hline \multicolumn{5}{|l|}{ Grip } \\
\hline Baseline & $31.2(11)$ & $32.6(14)$ & Reference & \\
\hline 3 weeks & $17.4(9)$ & $20.7(10)$ & $-2.1(-4.4$ to 0.2$)$ & 0.073 \\
\hline 6 weeks & $24.6(10)$ & $26.8(11)$ & $-1.2(-3.5$ to 1.1$)$ & 0.30 \\
\hline 3 months & $29.9(11)$ & 31.5 (11) & $-0.5(-2.8$ to 1.8$)$ & 0.69 \\
\hline \multicolumn{5}{|l|}{ Pinch } \\
\hline Baseline & $5.0(2.0)$ & $5.7(2.4)$ & Reference & \\
\hline 3 weeks & $4.3(1.9)$ & $5.2(2.2)$ & $-0.4(-0.9$ to 0.1$)$ & 0.095 \\
\hline 6 weeks & $5.3(1.8)$ & $6.2(2.1)$ & $-0.4(-0.9$ to 0.04$)$ & 0.070 \\
\hline 3 months & $6.0(1.8)$ & $6.7(2.2)$ & $-0.3(-0.8$ to 0.2$)$ & 0.15 \\
\hline
\end{tabular}

sis of their return to work. The study also reported better scores for the severity of symptoms of carpal tunnel syndrome in the endoscopic group during the first three months, because the open release group had essentially unchanged or only slightly improved scores (contrary to the results of previous studies). The second recent study, that did not describe its randomisation method, compared two portal endoscopic and open release and claimed no statistical difference between groups in time to return to work, without showing the data. ${ }^{9}$ The open group comprised only 32 patients, and their reported age implied that several may have been retired. The third study compared return to work data, based on patient recall, after one portal endoscopic (43 patients) and open surgery (42 patients) and reported shorter time after endoscopic release (mean, 18 and 26 days, respectively). An unknown number of patients had bilateral procedures. This study, with the longest follow-up of 12 weeks, also reported no differences in symptom severity and functional status scores or in pain measured with visual analogue scale. In all three studies, the timing of randomisation in relation to surgery was not stated and dropouts were excluded or not described.

\section{Generalisability of findings}

The findings of our randomised trial ought to be applicable to other countries since the trial entailed a randomised comparison of two groups. Although the length of sick leave may differ in different countries based on the health insurance system, labour rules, and other factors, ${ }^{4}$ this would have similarly influenced both groups. The finding of almost identical severity of symptoms of carpal tunnel syndrome and functional status scores and the small difference in postoperative pain shows that any substantially larger differences in return to work outcomes between the two methods in other countries would be unlikely. Even if a larger sample size might have detected a smaller differ- 
ence in sick leave, the difference might not be large enough for the endoscopic method to be more cost effective in this respect. A previous study using decision analysis showed that the endoscopic method would be more costly if the difference from the open release in mean time to return to work was less than 21 days. ${ }^{21}$

\section{Meaning of the study}

This study provides strong evidence that endoscopic carpal tunnel release yields a similar large degree of symptom relief and improvement in health related quality of life as open release. The $95 \%$ confidence intervals for the difference between the two groups in carpal tunnel syndrome symptom severity scores were smaller than clinically relevant values, which implies the equivalence of the methods regarding these outcomes. The two methods did not differ in complication rates, but repeat surgery was needed in two patients after endoscopic surgery and one patient after open surgery. Although concern has been raised about the risk of complications in endoscopic surgery, the reported incidence of serious complications, such as irreversible major injury to the nerve, has been low (none in the reportedly randomised studies and less than $2 \%$ in observational studies). ${ }^{20}$ A very large sample would therefore be needed for a trial to detect a possible difference in rate of serious complications.

Postoperative pain was self rated, and blinding the patients to the surgical procedure throughout follow-up would not have been possible. However, the finding that on repeated measurement occasions, the scores for severity of symptoms of carpal tunnel syndrome were highly similar, while postoperative pain showed a small difference consistently over time, implies it is less likely that non-blinding of patients caused the observed differences.

\section{Conclusion}

Considering the fact that endoscopic surgery is associated with higher direct costs, mainly of instrumentation, and although diminished postoperative pain may result in decreased need for therapy and rehabilitation costs, the small size of the benefit, the similar duration of work absence, and the possibility of a higher rate of repeat surgery make the cost effectiveness of endoscopic surgery uncertain.

Acknowledgment: We thank nurses and nurse assistants Pia Gunnarsson, Gunnel Glader, Britt-Marie Kastberg, Birgitta Åstedt, Kristina Karlsson, and Carin Ottosson at the outpatient surgery unit, department of orthopaedics, Kristianstad Hospital, for their help during the study.

Authors' contributions: IA was primarily responsible for designing, initiating, and conducting the study and data analysis and drafting of the manuscript and is guarantor. GUL, EO, MH, and RJ participated in conducting the study and critical review of the manuscript. JR participated in study design and data analysis and critical review of the manuscript.

Funding: This study was supported by research grants from Skane county council's research and development foundation, Kristianstad University, and the Swedish Society of Medicine.

Competing interest: None declared.

Ethical approval: Ethics Committee at Lund University (LU 365-97).

1 Owings MF, Kozak LJ. Ambulatory and inpatient procedures in the United States, 1996. National Center for Health Statistics. Vital Health Stat 1998;13: www.cdc.gov/ nchs/data/series/sr_13/sr13_139.pdf (accessed 25 May 2006).

2 Gerritsen AA, De Vet HC, Scholten RJ, Bertelsmann FW, de Krom MC, Bouter LM. Splinting vs surgery in the treatment of carpal tunnel syndrome: a randomized controlled trial. JAMA 2002;288:1245-51.

3 Bureau of Labor Statistics. Lost worktime injuries and illnesses: characteristics and resulting days away from work, 2001. USDL 03-138. Washington, DC: Bureau of Labor Statistics, 2003: www.bls.gov/iif/oshwc/osh/case/osnr0017.pdf (accessed 1 Jun 2006).

4 Katz JN, Amick BC, III, Keller R, Fossel AH, Ossman J, Soucie V, et al. Determinants of work absence following surgery for carpal tunnel syndrome. Am J Ind Med 2005; $47: 120-30$.
5 Chow JC. Endoscopic release of the carpal ligament: a new technique for carpal tunnel syndrome. Arthroscopy 1989;5:19-24.

6 Agee JM, McCarroll HRJ, Tortosa RD, Berry DA, Szabo RM, Peimer CA. Endoscopic release of the carpal tunnel: a randomized prospective multicenter study.J Hand Surg Am 1992;17A:987-95.

7 Brown RA, Gelberman RH, Seiler JG, Abrahamsson SO, Weiland AJ, Urbaniak JR, et al. Carpal tunnel release: a prospective, randomized assessment of open and endoscopic methods.J Bone Joint Surg Am 1993;75A:1265-75.

8 Trumble TE, Diao E, Abrams RA, Gilbert-Anderson MM. Single-portal endoscopic carpal tunnel release compared with open release: a prospective, randomized trial. $J$ Bone Joint Surg Am 2002;84:1107-15.

9 MacDermid JC, Richards RS, Roth JH, Ross DC, King GJ. Endoscopic versus open carpal tunnel release: a randomized trial. J Hand Surg Am 2003;28:475-80.

$10 \mathrm{Katz}$ JN, Stirrat CR. A self-administered hand diagram for the diagnosis of carpal tunnel syndrome. J Hand Surg Am 1990;15A:360-3.

11 Kimura J. Electrodiagnosis in diseases of nerve and muscle: principles and practice. 2nd ed. Philadelphia: FA Davis, 1989.

12 Atroshi I, Johnsson R, Sprinchorn A. Self-administered outcome instrument in carpal tunnel syndrome: reliability, validity and responsiveness evaluated in 102 patients. Acta Orthop Scand 1998;69:82-8.

13 Ware JE, Snow KK, Kosinski M, Gandek B. SF-36 health survey manual and interpretation guide. Boston: New England Medical Center, 1993.

14 Levine DW, Simmons BP, Koris MJ, Daltroy LH, Hohl GG, Fossel AH, et al. A self-administered questionnaire for the assessment of severity of symptoms and funcself-administered questionnaire for the assessment of severity of symptoms and
tional status in carpal tunnel syndrome. J Bome Joint Surg Am 1993;75A:1585-92.

15 Ware J, Kosinski M, Keller SD. A 12-item short-form health survey: construction of scales and preliminary tests of reliability and validity. Med Care 1996;34:220-33.

16 Elashoff JD. NQuery Advisor User's guide. Los Angeles, CA: Dixon Associates, 1995.

17 Guyatt GH, Osoba D, Wu AW, Wyrwich KW, Norman GR. Methods to explain the clinical significance of health status measures. Mayo Clin Proc 2002;77:371-83.

18 Altman DG. Confidence intervals for the number needed to treat. BMJ 1998;317:130912.

19 Kazis LE, Anderson JJ, Meenan RF. Effect sizes for interpreting changes in health status. Med Care 1989;27:S178-S189.

20 Thoma A, Veltri K, Haines T, Duku E. A meta-analysis of randomized controlled trials comparing endoscopic and open carpal tunnel decompression. Plast Reconstr Surg 2004;114:1137-46.

21 Vasen AP, Kuntz KM, Simmons BP, Katz JN. Open versus endoscopic carpal tunnel release: a decision analysis. J Hand Surg Am 1999;24A:1109-17.

(Accepted 1 April 2006)

doi 10.1136/bmj.38863.632789.1F

Department of Orthopaedics, Hässleholm and Kristianstad Hospitals, SE-281 25 Hässleholm, Sweden

Isam Atroshi associate professor

Gert-Uno Larsson orthopaedic surgeon

Ewald Ornstein orthopaedic surgeon

Department of Physical and Occupational Therapy, Kristianstad Hospital, SE-291 85 Kristianstad, Sweden

Manfred Hofer physical therapist

Department of Orthopaedics, Lund University Hospital, SE-221 00 Lund, Sweden

\section{What is already known about this topic}

Carpal tunnel syndrome is common among working persons and often requires surgery

Open surgery is effective but may be followed by prolonged pain at the scar or proximal palm delaying patient return to work; endoscopic surgery has been suggested to reduce these problems

Previous randomised studies were limited by unreported or inappropriate randomisation methods and inadequate number of employed patients

\section{What this study adds}

Endoscopic surgery is associated with modestly less pain than open surgery up to three months after operation but has no advantage regarding length of work absence

Both methods have equal efficacy in relieving symptoms of carpal tunnel syndrome

The small size of the benefit makes cost effectiveness of endoscopic surgery uncertain 


\section{Research}

Ragnar Johnsson associate professor

National Swedish Competence Centre for Musculoskeletal Disorders, Lund University Hospital
Jonas Ranstam biostatistician

Correspondence to: I Atroshi Isam.Atroshi@skane.se 